\title{
Roller coaster related fatalities, United States, 1994-2004
}

\author{
A R Pelletier, J Gilchrist
}

Injury Prevention 2005;11:309-312. doi: 10.1136/ip.2005.008425

\begin{abstract}
See end of article for authors' affiliations

....................

Correspondence to:

Dr A R Pelletier, Bureau of

Health, Maine Department

of Health and Human

Services, 286 Water

Street, Key Plaza, 8th

Floor, 11 State House

Station, Augusta, Maine

04333-0011; arp1@

cdc.gov
\end{abstract}

Accepted 12 May 2005

\begin{abstract}
Objective: To determine the number of fatalities related to roller coasters and examine factors common to multiple incidents.

Methods: A case was defined as the death of a person, which was associated with a roller coaster in the United States between 15 May 1994 and 14 May 2004. Cases were identified from four data sources: (1) Consumer Product Safety Commission, (2) Lexis-Nexis, (3) Medline, and (4) Saferparks.

Results: Forty people, ranging in age from 7 to 77 years, were killed in 39 separate incidents. Twenty nine (73\%) deaths occurred among roller coaster patrons. Eleven fatalities resulted from external causes related to injuries from falls or collisions. Eighteen people died from medical conditions that might have been caused or exacerbated by riding a roller coaster; 15 were the result of intracranial hemorrhages or cardiac problems. Eleven (28\%) deaths involved employees; all were caused by injuries.

Conclusions: Approximately four deaths annually in the United States are associated with roller coasters. Prevention of roller coaster fatalities is dependent on establishing an effective surveillance system for amusement ride injuries, engineering rides to better protect both patrons and employees, improving training and supervision of employees regarding safety precautions, and posting cautionary notices near roller coasters for people with specified medical conditions. Further research is needed on roller coaster related deaths resulting from intracranial hemorrhages and cardiac problems.
\end{abstract}

A roller coaster is as an amusement ride in which passengers are transported, often at high speeds, along an elevated railway, usually with sharp curves and steep inclines. The design features that provide a thrilling ride can result in severe injuries and death when a mishap occurs. No comprehensive system for monitoring injuries on amusement rides exists in the United States; however, the US Consumer Product Safety Commission (CPSC) estimated that 6900 non-occupational injuries requiring treatment in emergency departments occurred on amusement rides in $2003 .{ }^{1}$ Available data indicate that roller coasters account for $26 \%$ of injuries on amusement rides at fixed sites* and might be the leading cause of fatalities involving amusement rides. ${ }^{23}$ After the highly publicized death of a rider who fell from a roller coaster in Massachusetts in May 2004, ${ }^{4}$ we sought to identify all deaths related to roller coasters in the US during the past 10 years. Our objective was to document the magnitude of the problem and identify factors common to multiple incidents that might be amenable to prevention.

\section{METHODS}

Roller coaster related deaths were identified from four data sources: (1) the CPSC, (2) Lexis-Nexis, a computerized database of newspapers, (3) Medline, a computerized database of medical journals, and (4) Saferparks, an advocacy group that promotes amusement park safety. ${ }^{5}$ CPSC obtained its data from multiple sources (for example, death certificates, newspaper articles, reports of incident investigations, medical examiners, and the public). To obtain information on roller coaster related fatalities we requested CPSC data on any deaths related to amusement rides. Newspaper reports in Lexis-Nexis were identified using the search terms "roller coaster" and "death". Publications in Medline were identified using the search term "roller

${ }^{*}$ Amusement rides are categorized as fixed-site rides if they are permanently affixed to a site such as an amusement or theme park. Mobile rides are amusement rides that are moved from site to site as part of fairs and carnivals. coaster"; we reviewed all articles that were listed as of 1 March 2005. Saferparks obtained its data from a 2002 survey of state and county agencies responsible for regulating amusement ride safety. Roller coaster related fatalities were identified by reviewing information from Saferparks' online database. ${ }^{5}$ All fatalities reported by Saferparks that were not confirmed by another data source were verified by contacting the appropriate state or county agency that reported the death. After fatalities were identified, additional information was obtained, if needed, through follow up with CPSC and Saferparks and by conducting Internet searches.

A case was defined as the death of a person which was associated with a roller coaster in the United States between 15 May 1994 and 14 May 2004. Cause of death was categorized as a result of either external trauma or a medical condition based on available information. Deaths from external trauma were restricted to those with grossly obvious injuries. Data were abstracted by one author in a standard format and entered and analyzed in Epi Info $6 .{ }^{6}$ The Centers for Disease Control and Prevention determined the study was exempt from institutional review board oversight because the study did not involve any living persons.

\section{RESULTS}

Forty deaths related to roller coasters were identified during the 10 year study period. Thirty (75\%) deaths were identified from the CPSC, 29 (73\%) from Lexis-Nexis, 11 (28\%) from Saferparks, one $(3 \%)$ from Medline, ${ }^{7}$ and one $(3 \%)$ from another source. Twenty seven (68\%) deaths were identified by at least two sources.

The 40 deaths were the result of 39 incidents. Thirty seven (93\%) of the fatalities occurred on roller coasters at fixed sites. Deaths occurred in 20 states; five states (California $(\mathrm{n}=8)$, Florida $(\mathrm{n}=4)$, Ohio $(\mathrm{n}=4)$, Nevada $(\mathrm{n}=3)$, New Jersey $(\mathrm{n}=3)$ ) accounted for $55 \%$ of all deaths. One roller coaster had three fatalities as the result of separate incidents; no other roller coaster was associated with more than one

Abbreviations: CPSC, Consumer Product Safety Commission. 
fatal incident. Thirty two (80\%) fatalities occurred during May through September. Decedents ranged in age from 7 to 77 years (median 29 years); 10 (25\%) fatalities involved children $<18$ years of age (table 1). Twenty two (55\%) decedents were female.

Twenty nine $(73 \%)$ deaths occurred among roller coaster patrons (fig 1). Eleven people died from external causes (nine fell or were ejected from a roller coaster; one person standing on the ground was struck by a passenger in a moving roller coaster; and one person suffered blunt abdominal trauma after the roller coaster came to a sudden stop). Four of these 11 deaths were due to mechanical failure (for example, derailments and collisions), three to rider misconduct (for example, disabling safety devices or entering restricted areas), three to failure of restraint systems, and one to disputed causes (that is, rider misconduct versus failure of restraint system).

Eighteen people, 14 of whom were female, died from medical conditions that might have been caused or exacerbated by riding a roller coaster (eight intracranial hemorrhages, seven heart conditions, one asthma attack, one aortic laceration, and one unknown). Of these 18 deaths, five involved people who were aware of a pre-existing medical condition. Two of these had a history of heart disease; two who died of intracranial hemorrhages were on anticoagulants; and one had asthma.

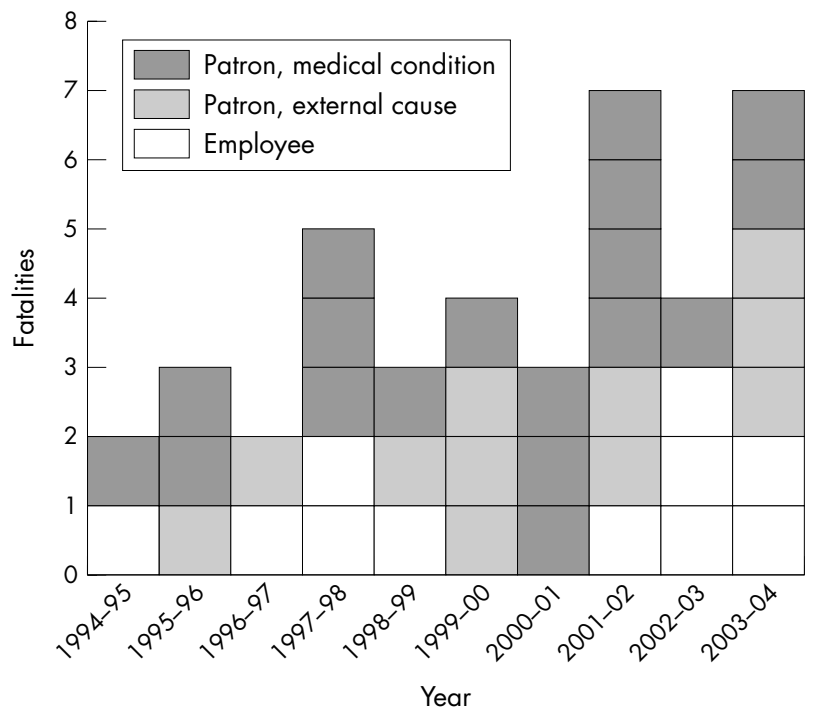

Figure 1 Roller coaster related fatalities by type, United States, 15 May 1994-14 May 2004

Table 1 Roller coaster related fatalities, United States, 15 May 1994-14 May 2004

\begin{tabular}{|c|c|c|c|c|c|}
\hline Case & Age & Sex & Patron/employee & Cause of death & Description of incident \\
\hline 1 & 14 & $\mathrm{~F}$ & Patron & Medical condition & Collapsed on ride; died of cardiac condition \\
\hline 2 & 25 & M & Employee & External trauma & Caught in moving equipment while attempting to cross tracks \\
\hline 3 & 13 & $\mathrm{~F}$ & Patron & Medical condition & Collapsed on ride; died of cardiac arrhythmia \\
\hline 4 & 77 & M & Patron & Medical condition & $\begin{array}{l}\text { Died } 13 \text { days after bumping head on ride and developing subdural hematoma; was on } \\
\text { anticoagulants }\end{array}$ \\
\hline 5 & 14 & $\mathrm{~F}$ & Patron & External trauma & Ejected from ride either from failure of restraints or while attempting to stand \\
\hline 6 & 25 & $\mathrm{~F}$ & Employee & External trauma & Hit by roller coaster while crossing track \\
\hline 7 & 14 & M & Patron & External trauma & Ejected from ride after collision with car whose anti-rollback device failed \\
\hline 8 & 14 & $\mathrm{~F}$ & Patron & Medical condition & Died of asthma attack after roller coaster ride; had history of asthma \\
\hline 9 & 49 & M & Patron & Medical condition & Died 1 day after ride from complications of subdural hematoma \\
\hline 10 & 44 & $\mathrm{~F}$ & Employee & External trauma & Fell from roller coaster catwalk; was intoxicated \\
\hline 11 & 51 & M & Employee & External trauma & Struck by roller coaster while working on track \\
\hline 12 & 56 & $\mathrm{~F}$ & Patron & Medical condition & $\begin{array}{l}\text { Lapsed into unconsciousness shortly after ride; died } 1 \text { day later of intracranial } \\
\text { hemorrhage }\end{array}$ \\
\hline 13 & 40 & M & Employee & External trauma & Struck in head by roller coaster while trimming grass under ride \\
\hline 14 & 25 & M & Patron & External trauma & Struck in head by passenger's leg while attempting to retrieve hat from restricted area \\
\hline 15 & 46 & $\mathrm{~F}$ & Patron & Medical condition & Died 14 days after ride of subdural hematoma; was on anticoagulants \\
\hline 16 & 20 & M & Patron & External trauma & Ejected from ride after freeing himself from safety restraints \\
\hline 17 & 39 & $\mathrm{~F}$ & Patron & External trauma & Ejected from ride after anti-rollback device failed \\
\hline 18 & 8 & $\mathrm{~F}$ & Patron & External trauma & Ejected from ride after anti-rollback device failed \\
\hline 19 & 12 & M & Patron & Medical condition & Suffered respiratory arrest while on roller coaster; cause of death unknown \\
\hline 20 & 58 & $\mathrm{~F}$ & Patron & Medical condition & Lapsed into unconsciousness on ride; died 2 days later of intracranial hemorrhage \\
\hline 21 & 30 & M & Patron & Medical condition & Died 1 hour after ride of heart attack \\
\hline 22 & 23 & $\mathrm{~F}$ & Patron & Medical condition & Collapsed following ride; died of intracranial hemorrhage \\
\hline 23 & 28 & $\mathrm{~F}$ & Patron & Medical condition & Collapsed on ride; died of ruptured cerebral aneurysm \\
\hline 24 & 23 & M & Employee & External trauma & Hit in head by roller coaster while trimming weeds under track \\
\hline 25 & 20 & $\mathrm{~F}$ & Patron & Medical condition & Found unresponsive at end of ride; died of ruptured cerebral aneurysm \\
\hline 26 & 52 & $\mathrm{~F}$ & Patron & Medical condition & Lapsed into unconsciousness on ride; died of heart attack \\
\hline 27 & 7 & M & Patron & External trauma & $\begin{array}{l}\text { Died of internal abdominal injuries after being thrown forward when ride came to } \\
\text { abrupt stop }\end{array}$ \\
\hline 28 & 16 & $\mathrm{~F}$ & Patron & Medical condition & Died 1 hour after ride of aortic laceration; had Marfan's Syndrome \\
\hline 29 & 39 & $\mathrm{~F}$ & Patron & External trauma & Ejected from ride after failure of restraints; was morbidly obese \\
\hline 30 & 58 & M & Employee & External trauma & Struck in head by patron's legs while in restricted area \\
\hline 31 & 48 & M & Employee & External trauma & Fell from aerial lift while painting roller coaster \\
\hline 32 & 43 & M & Employee & External trauma & Hit from behind by roller coaster while performing maintenance \\
\hline 33 & 11 & $\mathrm{~F}$ & Patron & Medical condition & Found unresponsive after ride; died of cardiac condition \\
\hline 34 & 32 & $\mathrm{~F}$ & Patron & External trauma & Ejected from ride while attempting to stand \\
\hline 35 & 34 & $\mathrm{~F}$ & Patron & Medical condition & Collapsed on ride and died of heart attack \\
\hline 36 & 40 & M & Employee & External trauma & Caught by moving equipment while performing maintenance and thrown to his death \\
\hline 37 & 22 & M & Patron & External trauma & Ejected from ride after roller coaster car derailed \\
\hline 38 & 34 & $\mathrm{~F}$ & Patron & Medical condition & Collapsed on ride and died of heart attack \\
\hline 39 & 21 & $\mathrm{~F}$ & Employee & External trauma & Struck by roller coaster while crossing track \\
\hline 40 & 55 & M & Patron & External trauma & Ejected from ride after failure of restraints; was morbidly obese and had cerebral palsy \\
\hline
\end{tabular}


Eleven (28\%) deaths involved employees; all involved external causes related to injuries. Seven people were struck by roller coasters; two fell from heights; and two became entangled in moving equipment.

\section{DISCUSSION}

Approximately four deaths annually in the United States are associated with roller coasters. Although traumatic injuries resulting in the deaths of roller coaster patrons tend to receive the most media attention, they only represent one quarter of all fatalities. Approximately half of deaths associated with roller coasters occur from medical conditions in people without external signs of injury. The underlying cause of these deaths can be difficult to determine; however, a number of reports have documented similar, but non-fatal, neurological, vascular, and connective tissue problems related to riding roller coasters. ${ }^{8-15}$ The remaining quarter of deaths associated with roller coasters are occupational fatalities, which often receive limited attention.

The overall number of roller coaster related fatalities from this case series is larger than what has been previously reported by other groups. ${ }^{35}$ This is due to the use of multiple data sources for reporting and the inclusion of both deaths from medical causes without external signs of trauma and occupational fatalities.

The lack of an effective system to monitor injuries and deaths involving roller coasters is part of a larger problem. No single agency has responsibility for tracking incidents involving amusement rides. The CPSC has authority for tracking injuries to patrons of amusement rides that are mobile $^{3}$ but does not have legislative authority to track incidents on rides at fixed sites. This is often the responsibility of state or local agencies; however, a number of states have no regulations or specifically exempt large facilities from review. ${ }^{8}$ Occupational safety and health agencies, either at the state or federal level, monitor work related injuries. This approach to monitoring injuries results in a fragmented system that produces data of limited value from a public health perspective.

Quantifying the risk of death associated with roller coasters was not possible as there are no reliable estimates for the number of people riding roller coasters annually in the US. An industry trade group estimated that the injury risk for fixed site amusement rides compared favorably to other recreational activities; ${ }^{2}$ however, the public's tolerance for risk may be lower for recreational activities in which the participant is passive (for example, riding a roller coaster) rather than active (for example, playing football). Although the number of deaths related to roller coasters is small in comparison to the leading causes of unintentional injury mortality (that is, motor vehicle crashes, falls, drowning), the public health impact is substantial when injuries for all types of amusement rides are considered. ${ }^{13}$ Efforts to improve safety for roller coasters would be applicable to other types of amusement rides and therefore could prevent a significant number of injuries and deaths.

This study is subject to at least four limitations. Firstly, case detection might have been incomplete. This might have been more of a problem for occupational fatalities because these deaths tended to generate less media attention, a major source for identifying cases. Secondly, we relied on the reporting sources to determine what constituted a roller coaster. This might have resulted in the inclusion of certain rides that were not characteristic of traditional roller coasters. Thirdly, limited information was available for many of the fatalities (for example, results of drug and alcohol testing were known for only two cases). The number of decedents who reportedly knew about pre-existing medical conditions represents a minimum estimate of the true prevalence.

\section{Key points}

- This study is the first published case series of roller coaster related deaths.

- Cases were identified using multiple data sources and included occupational fatalities.

- Approximately one half of roller coaster related fatalities were due to external trauma.

- The remaining deaths were the result of medical conditions, most often intracranial hemorrhage and cardiac problems.

- Approaches to preventing roller coaster related fatalities are discussed.

Fourthly, attributing deaths to roller coasters without external signs of trauma might overestimate the true number of cases. Three quarters of the deaths related to roller coasters that were the result of medical conditions were from heart disease and stroke, two of the three leading causes of death in this country. Temporal association alone does not prove causation.

On the basis of our findings, we make the following recommendations. Firstly, an effective surveillance system to monitor injuries and deaths related to amusement rides is needed. Much of the infrastructure for such a system already exists within the CPSC and state and local governments, but no agency has been given overall responsibility to coordinate efforts. Secondly, rides need to be engineered to better protect riders and employees. For example, rides might be designed to automatically shut down if a patron releases a restraint system or an employee leaves a designated safe area. Thirdly, enhanced training and supervision are needed for employees. This would likely improve safety for both employees and patrons. Fourthly, highly visible cautionary notices posted near roller coasters might alert those with specified medical conditions to avoid these rides. Finally, further research is needed on roller coaster related deaths resulting from intracranial hemorrhages and cardiac problems to determine what role, if any, roller coasters play in these deaths.

\section{ACKNOWLEDGEMENTS}

We gratefully acknowledge the assistance of Kathy Fackler, Carol Firman, Vicky Leonard, Alice Pelletier, Leigh Ramsey, and Joyce Verdone.

\section{AUTHOR CONTRIBUTIONS}

As principal investigator, Dr Pelletier had full access to all of the data in the study and had final responsibility for the decision to submit for publication. Study concept and design: Pelletier, Gilchrist. Acquisition of data: Pelletier. Analysis and interpretation of data: Pelletier, Gilchrist. Drafting of the manuscript: Pelletier. Critical revision of the manuscript for important intellectual content: Pelletier, Gilchrist.

\section{Authors' affiliations}

A R Pelletier, Division of Public Health Partnerships, National Center for Health Marketing, Centers for Disease Control and Prevention, Atlanta, GA, USA

J Gilchrist, Division of Unintentional Injury Prevention, National Center for Injury Prevention and Control, Centers for Disease Control and Prevention, Atlanta, GA, USA

Funding: there was no external funding for this study. The work was conducted by federal employees with the Centers for Disease Control and Prevention.

Conflicts of interest: the authors report no conflicts of interest. 
Role of funding source: the Centers for Disease Control and Prevention reviewed and approved the manuscript.

\section{REFERENCES}

1 Levenson MS. Amusement ride-related injuries and deaths in the United States: 2004 update. Bethesda, Maryland: Consumer Product Safety Commission, 2004.

2 Heiden EJ, McGonegal S. 2001-2002 fixed-site amusement ride injury survey analysis. Injury Insights, June/July 2003.

3 Levenson MS. Amusement ride-related injuries and deaths in the United States: 2002 update. Bethesda, Maryland: Consumer Product Safety Commission, 2002.

4 Paige C. Demand for answers after fatal fall; mother wonders why disabled son was allowed to get on roller coaster. Boston Globe 2004 May 3. Section B: 1 .

5 Saferparks. Saferparks ride incident database. Available at www.saferparks.org (accessed 2 August 2005).

6 Dean AG, Dean JA, Coulombier D, et al. Epi Info, Version 6: A Word Processing, Database, and Statistics Program for Epidemiology on
Microcomputers. Atlanta, GA: US Dept of Health and Human Services, Centers for Disease Control and Prevention, 1994.

7 Synder RW, Sridharan ST, Pagnanelli DM. Subdural hematoma following roller coaster ride while anticoagulated. Am J Med 1997;102:488-9.

8 Braksiek RJ, Roberts DJ. Amusement park injuries and deaths. Ann Emerg Med 2002;39:65-72.

9 Blacker DJ, Wiidicks EF. A ripping roller coaster ride. Neurology 2003:61:1255.

10 Huang PP. Roller coaster headaches revisited. Surg Neurol 2003;60:398-401.

11 Stahlfeld DR, Roozrokh HC. Traumatic bilateral ECCA injury in a roller coaster enthusiast. Ann Vasc Surg 2002;16:505-8.

12 Lascelles K, Hewes D, Ganesan V. An unexpected consequence of a roller coaster ride. J Neurol Neurosurg Psychiatr 2001;71:704-5.

13 McBeath JG, Nanda A. Roller coaster migraine: an underreported injury? Headache 2000;40:745-7.

14 Bogen JE. Roller coaster headache and subdural hematoma. Neurology 2000;55:903.

15 Andrews RM, Bell RW, Jayamanne DG, et al. 'Roller coaster glaucoma': an unusual complication of Marfan's syndrome. Eye 1994;8:358-60.

\section{LACUNAE}

\section{Amusement park manager found guilty of reckless homicide}

A

jury convicted the former manager of a Tennessee amusement of reckless homicide for a woman's fatal fall from a pendulum-like ride known as The Hawk in March 2004. It opted not to convict the defendant of second-degree murder for the death of June Alexander, who fell 60 feet to her death from a ride after her harness came loose in mid-air as her family watched. The sentence on the lesser charge could be up to four years or as little as probation. June Alexander was celebrating her son's 15th birthday at the park when the accident occurred. Prosecutors argued that the safety system on The Hawk, which swings higher and higher before turning 360 degrees, had been tampered with, causing the ride to take off even though Alexander's safety harness was not secured. Jumper cables were found in the system's electrical panel, which expert witnesses testified had bypassed the backup safety mechanisms. Outside the courtroom, the Sevier County District Attorney General said he believed the strongest piece of evidence against the defendant was a videotape made by a technician for The Hawk's Italian manufacturer, Zamperla. The video demonstrated the effect of the defective cables, which allowed the ride to take off without the safety harnesses locked in place. The technician said that if the ride's automatic safety mechanisms were in place, The Hawk never would have begun its deadly ascent.

Reported by CNN and other media outlets. Contributed by Barry Pless. 